\title{
HIATO ENTRE ATITUDE E COMPORTAMENTO NO DESCARTE E RECICLAGEM DE LIXO: UMA ABORDAGEM INTERGERACIONAL
}

\section{GAP BETWEEN ATTITUDE AND BEHAVIOR IN THE DISPOSAL AND RECYCLING OF TRASH: AN INTERGENERATIONAL APPROACH}

Lara Coelho Vaccari

Pontifícia Universidade Católica do Rio de Janeiro

Rio de Janeiro, RJ, Brasil

E-mail: laracv@terra.com.br

\section{Marcos Cohen}

Professor assistente do departamento de Administração da Pontifícia Universidade Católica do Rio de Janeiro

Rio de Janeiro, RJ, Brasil

E-mail: mcohen@iag.puc-rio.br

Angela Maria Cavalcanti da Rocha

Professora associada do departamento de Administração da Pontifícia Universidade Católica do Rio de Janeiro

Rio de Janeiro, RJ, Brasil

E-mail: angelarocha@iag.puc-rio.br

\section{RESUMO}

A partir da constatação por diversos autores da existência de um hiato entre a atitude ecologicamente consciente de consumidores e seu efetivo comportamento, tanto em termos de compras quanto de hábitos pessoais de consumo, este artigo investiga tal fenômeno por meio de uma pesquisa exploratória qualitativa. Buscou-se identificar os fatores que aumentam e diminuem este hiato, focando especificamente no descarte e reciclagem de lixo sob a perspectiva de consumidores das gerações baby boomer e Y. Para isso, foram realizadas trinta entrevistas em profundidade com consumidores residentes no Rio de Janeiro. Utilizou-se o software Atlas.ti para realizar a análise de conteúdo das entrevistas. Os resultados apontam as principais semelhanças e diferenças encontradas entre os comportamentos das duas gerações e sugerem um comportamento mais motivado por preocupações ambientais dos indivíduos da geração $Y$ da amostra. Ao final, foi desenvolvido um esquema conceitual que reúne os fatores identificados no decorrer do estudo, classificando-os em três grandes grupos: fatores antecedentes, fatores que reduzem o hiato e fatores que aumentam o hiato.

Palavras-chave: Atitude pro-ambiental. Comportamento ecologicamente consciente. Hiato. Descarte. Reciclagem.

\section{ABSTRACT}

Based on the observation by several authors of the existence of a gap between the ecologically conscious attitude of consumers and their effective behavior, both in terms of purchase and personal consumption habits, this article investigates this phenomenon through a qualitative exploratory research. We sought to identify the factors that increase and decrease this gap, specifically focusing on waste disposal and recycling from the perspective of consumers of the baby boomer and $Y$ generations. For this, thirty indepth interviews were conducted with consumers residing in Rio de Janeiro. We used the software Atlas.ti to perform the content analysis of the interviews. The results point out the main similarities and differences found between the behaviors of the two generations and suggest a behavior more motivated by environmental concerns of the sampled individuals of generation Y. Finally, a conceptual scheme was developed that brings together the factors identified during the study, classifying them into three major groups: antecedent factors, factors that reduce the gap and factors that increase the gap.

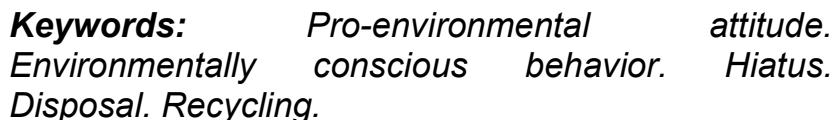
Disposal. Recycling.

Data de submissão: 11 de dezembro de 2016.

Data de aprovação: 10 de junho de 2017. 


\section{INTRODUÇÃO}

Ainda que as preocupações com as mudanças climáticas estejam em evidência, os desafios atuais de governos e organizações não se limitam às questões ambientais, mas englobam também a questão de sustentabilidade com a preocupação de manter o equilíbrio no tripé econômico, social e ambiental (FRIEND, 2009). A busca pela sustentabilidade não é, contundo, uma responsabilidade somente de governos e empresas, mas também dos indivíduos, seja como cidadãos, seja como consumidores. A partir da década de 90, verificou-se uma mudança na atitude e no comportamento dos consumidores em relação a questões ambientais, da indiferença à preocupação, impulsionada por vários fatores, sobretudo maior cobertura de mídia, legislação mais rigorosa e maior envolvimento dos grupos de pressão ambiental (ROBERTS e BACON, 1997). Nos últimos anos, o interesse dos consumidores por questões ecológicas aumentou dramaticamente com um correspondente incremento no envolvimento em atividades em favor do meio ambiente, tais como uso de embalagens recicláveis, economia de energia e compostagem de alimentos (MOSTAFA, 2007).

Dessa forma, compreender as motivações, atitudes e comportamentos dos consumidores em relação a questões ecológicas é de suma importância para aliviar parte dos problemas associados com o meio ambiente (ROBERTS e BACON, 1997). Além disso, uma compreensão mais profunda das características dos consumidores ecologicamente conscientes pelas organizações pode levar à criação de programas de sustentabilidade mais eficientes e programas de marketing mais eficazes (RUNDLE-THIELE, PALADINO, APOSTOL, 2008). Entende-se por consumidores ecologicamente conscientes aqueles que adquirem produtos e serviços que percebem ter um impacto positivo (ou menos negativo) sobre o meio ambiente, se preocupam com causas sociais e que, por meio de suas atitudes e ações, buscam alcançar o consumo sustentável, tendo em vista as limitações de recursos do planeta (ROBERTS, 1996),

Por outro lado, tem sido constatada por estudiosos do consumo mais responsável em relação ao meio ambiente uma lacuna entre a atitude pró-ambiental de diferentes consumidores e seu comportamento efetivo, seja de compra de produtos e serviços, nas escolhas referentes ao consumo de recursos escassos, como água e energia, ou ainda em sua atitude perante o descarte de lixo e da reciclagem de materiais (PADEL e FOSTER, 2005; PAÇO e RAPOSO, 2010; YOUNG, HWANG, MCDONALD e OATES, 2010). Em outras palavras, muitas vezes, uma pré-disposição ou atitude favorável ao meio ambiente não se transforma em um comportamento de compra ou ação ecológica.

Quando se considera esta lacuna atitude-comportamento pela lente das gerações de consumidores, identifica-se que embora vários estudos já tenham comparado grupos de coorte geracional e seu comportamento de consumo para vários produtos, tais como alimentos (BUGERA, LENGYEL e UTIOH, 2013), consumo de vinhos (POMARICCI e VECCHIO, 2014); viagem e turismo (LI, LI e HUDSON, 2013), telefonia celular (KUMAR e LIM, 2008), vestuário esportivo (RAHULAN et al., 2013), nenhum estudo empírico foi encontrado que focasse as diferenças entre gerações relacionadas à compreensão do hiato entre atitude e comportamento ecologicamente conscientes. 
Tendo em vista o contexto apresentado e a falta de estudos sobre o tema, foram formuladas as seguintes questões centrais tratadas nesse artigo:

- Quais os principais fatores influenciadores no hiato entre atitudes e comportamento ecologicamente conscientes nas gerações baby boomer e $Y$ ?

- Os fatores influenciadores do hiato identificados afetam de forma distinta os membros das gerações baby boomer e $Y$ ?

Assim, o objetivo final da pesquisa foi identificar e comparar os fatores que se encontram associados ao hiato entre atitudes e comportamento ecologicamente conscientes nas gerações baby boomer e $Y$ em diferentes atividades de consumo. Este artigo traz um recorte da pesquisa maior focando nas atitudes e comportamentos de consumidores em relação ao descarte de lixo e à reciclagem de materiais.

\section{REFERENCIAL TEÓRICO}

\section{Marketing Verde e Consumidor ecologicamente consciente}

De acordo com Weldford (1995), o marketing verde refere-se ao fornecimento de informações sobre o produto e produtor ao consumidor, proporcionando-Ihe conselhos sobre a utilização, reparação, reciclagem e rejeição desse produto. Dessa forma, o marketing verde não se resume apenas à promoção, mas envolve ampla adoção de políticas ambientais que englobam todo o composto mercadológico (desde a qualidade do produto, sua embalagem, transporte, consumo e descarte) e a conscientização do consumidor. Neste sentido, é importante a criação de produtos que tenham uma cadeia de produção, transporte, consumo e descarte na natureza de forma responsável, diminuindo assim os resíduos tóxicos (OTTMAN, STAFFORD e HARTMAN, 2006).

Além disso, destaca-se a importância de compreender e adotar padrões de consumo sustentáveis que consistem em adquirir, utilizar e descartar bens e serviços com respeito ao meio ambiente e à dignidade humana. Um ponto a ser considerado na busca da sustentabilidade é a preocupação com o destino do produto ao final de seu ciclo de vida, o pós-consumo (ex: pilhas, baterias, lâmpadas, sacolas plásticas, pneus etc.), um assunto que antes era irrelevante para as empresas e agora vem ganhando grande destaque no cenário mundial (OTTMAN, 1998).

Este estudo utiliza a terminologia de Roberts (1996) de "consumidor ecologicamente consciente", definido como aquele que adquire produtos e serviços que percebe ter um impacto positivo (ou menos negativo) sobre o meio ambiente, se preocupa com causas sociais e que busca alcançar o consumo sustentável. 


\section{Os fatores que afetam o hiato entre atitude pró-ambiental e comportamento}

Pesquisas acadêmicas em Marketing vêm constatando que, apesar do aumento da consciência e do interesse do consumidor por produtos e serviços ecologicamente corretos, e de uma pré-disposição para compra de produtos mais sustentáveis, há muitas vezes falta de correspondência nos consumidores entre seu discurso e suas ações, isto é, uma incoerência entre suas atitudes e seu comportamento (PADEL e FOSTER, 2005; PAÇO e RAPOSO, 2010; YOUNG et al., 2010; THOGERSEN e SCHRADER, 2012). Esta incoerência, aqui chamada de hiato entre atitude e comportamento, pode ser estendida também ao comportamento diário, por exemplo, quando pessoas que afirmam serem conscientes em relação ao meio ambiente deixam de utilizar sacolas reutilizáveis em suas compras em supermercados, ou tomam banhos mais longos ou, ainda, não se preocupam em separar ou reciclar o lixo doméstico (Stern, 2000). Verifica-se assim, que muitas vezes a atitude ecológica ou pró-ambiental não se transforma em comportamento de compra ou hábito favorável ao meio ambiente.

Arbuthnott (2012) também reconhece o hiato entre atitudes e comportamento do consumidor ecologicamente consciente. A autora considera que para transformar as atitudes pro-ambientais em comportamentos e ações efeitivamente ecológicas seria preciso quebrar duas barreiras: os hábitos e as necessidades psicológicas.

Alguns autores se preocupam em investigar fatores que afetariam positiva e negativamente o comportamento ecologicamente consciente, isto é, reduzindo ou aumentando o hiato entre a atitude próambiental e o comportamento real que foge deste padrão. Entre estes se destacam os fatores motivacionais e contextuais, e as restrições externas e internas. Cada um desses fatores é abordado a seguir.

\section{Fatores motivacionais e contextuais}

Para Steg e Vlek (2009) há três linhas de pesquisa que focam em diferentes fatores motivacionais como principais influenciadores do comportamento ambiental do consumidor. São elas:

1. Custos versus benefícios - muitos autores partem da premissa que os consumidores fazem escolhas racionais e escolhem alternativas com maiores benefícios e menores custos (em termos de dinheiro, esforço e/ou aprovação social).

2. Preocupações morais e normativas - vários estudos focam no papel das preocupações morais e normativas, subjacentes ao comportamento ambiental a partir de diferentes perspectivas teóricas. Segundo Steg e Vlek (2009) diversos trabalhos evidenciam que os indivíduos que mais fortemente possuem valores pró-sociais e altruístas têm maior probabilidade de apresentarem um comportamento pró-ambiental.

3. Afeto - Alguns estudos explicitamente examinaram o papel do afeto na explicação do comportamento ambiental (GATERSLEBEN, 2007). 
Steg e Vlek (2009) apontam para uma perspectiva integradora da motivação ambiental, afirmando que as três linhas gerais de pesquisa anteriormente descritas envolvem diferentes antecedentes de comportamento ambiental e provam ser capazes de predizer, pelo menos, alguns tipos de comportamento ambiental. No entanto, ainda não estaria claro qual perspectiva seria mais útil e em que situação.

\section{Restrições Externas e Internas}

Segundo Pride e Ferrel (2001) e Urdan e Urdan (2010, também podem ser destacadas influências contextuais, ou situacionais, sobre o comportamento dos consumidores, Elas decorrem de circunstâncias de tempo e de localização que afetam o processo de decisão de compra, sendo, portanto, externas a eles e muitas vezes fora de seu controle. Um exemplo seria o aumento da coleta seletiva e da reciclagem por um indivíduo após terem dido construídas instalações apropriadas em seu prédio residencial.

Thogersen (2005) afirma que tanto as restrições externas como as restrições e limitações pessoais dos consumidores influenciam qualquer tentativa consciente para mudar o estilo de vida. Como restrições externas para mudanças no estilo de vida, ele destaca as condições naturais, tais como o clima; a infraestrutura social disponível; a distribuição do produto e seu preço; e a incerteza do consumidor quanto à sustentabilidade das opções disponíveis decorrente da falta de esclarecimentos ou de regulamentação apropriada. Steg e Vlek (2009), concordam com Thogersen (2005) ao afirmarem que há muitos fatores contextuais (externos) que podem facilitar ou restringir o comportamento ambiental e influenciar as motivações individuais. Assim, é importante não só considerar os fatores internos, de caráter pessoal, tais como atitudes, valores, hábitos, mas também fatores contextuais tais como infraestrutura física, instalações técnicas, a disponibilidade e as características dos produtos e serviços.

$O$ aspecto da percepção individual também é abordado por alguns autores. O modelo de Comportamento Ambiental de Hines, Hungerford e Tomera (1986) identifica o lócus de controle como um construto que representa a percepção do indivíduo quanto a sua capacidade de realizar mudanças por meio de seu próprio comportamento. Indivíduos com forte lócus de controle interno acreditam que suas ações podem produzir mudanças e que podem interferir no curso dos acontecimentos. Por outro lado, indivíduos com forte lócus de controle externo consideram insignificante o impacto de suas ações e sentem que as mudanças só podem ser realizadas por outros indivíduos que detêm o poder.

São apresentados a seguir dois modelos que buscam abordar a questão do hiato, sobretudo pela ótica das restrições (barrreiras) internas e externas ao comportamento ecologicamente consciente. 
Modelo de Barreiras de Preocupações Ambientais e Ações de Blake (1999).

O modelo de Blake (1999) tenta abordar a diferença de atitude e comportamento, explicando o hiato encontrado nesse processo. Ele aponta que a maioria dos modelos de comportamento pró-ambiental são limitados porque não levam em conta as restrições do indivíduo, sociais e institucionais, supondo que os seres humanos são racionais e fazem uso sistemático da informação disponível a eles (Kollmuss e Agyeman, 2002).

Figura 1: Barreiras entre preocupação ambiental e ação de Blake (1999)

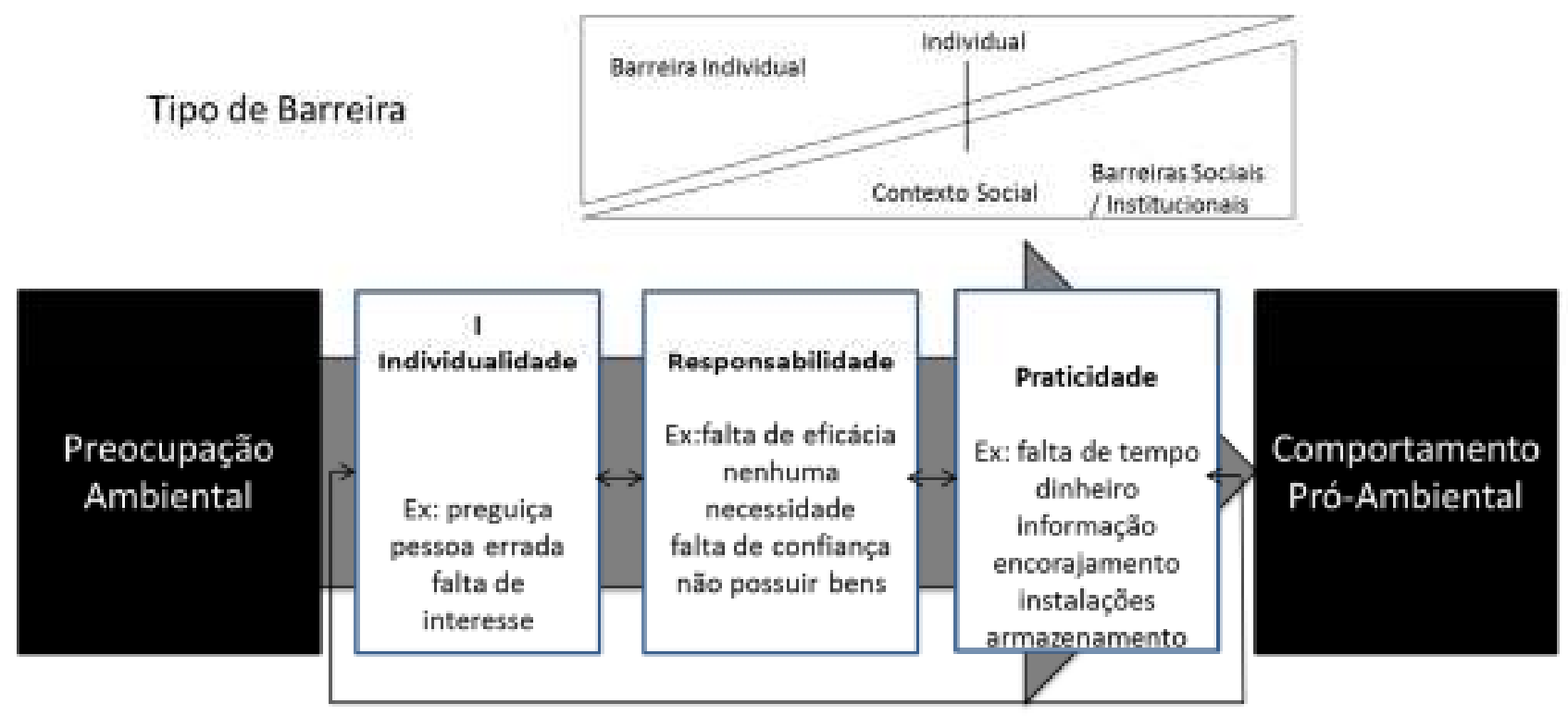

Fonte: Adaptado de Blake (1999, p. 267).

Conforme apresentado no modelo da figura 1, Blake (1999) identifica três barreiras para a ação: individualidade, responsabilidade e praticidade.

(1) Barreiras Individuais - São barreiras psicológicas que se encontram dentro da pessoa (intrínsecas), e estão relacionadas com atitude e temperamento individual. Essas barreiras têm maior influência sobre indivíduos que não têm forte preocupação ambiental. Assim, a preocupação ambiental é, de certa forma, compensada por outras atitudes conflituosas.

(2) Barreiras de Responsabilidade - Encontram-se muito próximas da noção de "lócus de controle". Assim, as pessoas que não agem de forma pró-ambiental sentem que não podem influenciar a situação ou não deveriam ter a responsabilidade de fazê-lo.

(3) Barreira de Praticidade - Está relacionada aos constrangimentos sociais e institucionais que impedem as pessoas de agir em prol do meio-ambiente, independentemente de suas atitudes ou intenções. Blake enumera restrições, tais como falta de tempo, falta de dinheiro, falta de informação e falta de acesso. 
Segundo Kollmuss e Agyeman (2002), embora o modelo de Blake seja muito útil, ao combinar fatores externos e internos e descrevê-los com alguns detalhes, não leva em conta os fatores sociais, tais como pressões familiares e normas culturais, nem explora com maior profundidade os fatores psicológicos (por exemplo, o que significa "não ter tempo"?).

Modelo ABC (Attitude, Behaviour, Context) de Stern (2000).

O modelo ABC (Attitude, Behavior, Context) de Stern (2000) é considerado relevante na tentativa de desenvolver um modelo significativo e integrado para explicar o comportamento ambiental e as restrições de atitude e comportamento. Também apresenta relevância para superar a dicotomia internalista-externalista encontrada na literatura da psicologia social (Jackson, 2005).

A abordagem de Stern parte do ponto principal do entendimento de que o comportamento é uma função do organismo e de seu ambiente. Ou seja, na linguagem do modelo $A B C$, o comportamento ( $B$ behavior) é "um produto interativo de variáveis da esfera de atitudes pessoais (A - attitude) e fatores contextuais (C - context)" (Stern, 2000, p. 415). As variáveis de atitudes (A) podem incluir uma variedade de crenças pessoais específicas, normas, valores e pré-disposições para atuar de determinadas maneiras. No entanto, os fatores contextuais $(C)$ potencialmente podem incluir uma grande variedade de influências, como: incentivos monetários e custos, capacidades físicas e constrangimentos, fatores institucionais e legais, apoio de políticas públicas, influências interpessoais (pressões de grupos sociais, fidelidade e participação em grupos ambientais).

Um ponto chave do modelo $A B C$ é a dinâmica estrutural entre a influência de atitudes (fatores internos) e contexto (fatores externos). Os defensores do modelo $A B C$ afirmam que o elo entre atitude e comportamento é mais forte quando o contexto (conjunto de fatores externos) é fraco ou inexistente. Por outro lado, afirmam que não há praticamente nenhuma ligação entre atitude e comportamento quando esse contexto (fatores externos) é fortemente negativo ou fortemente positivo (Jackson, 2005).

Assim, por exemplo, no caso da reciclagem, quando o acesso às instalações de reciclagem é muito difícil ou muito fácil, pouco importa se as pessoas têm ou não atitudes de pró-reciclagem, uma vez que, no primeiro caso, praticamente ninguém recicla e, no segundo, a maioria recicla. Entretanto, em uma situação em que é possível reciclar, mas não é necessariamente fácil, a correlação entre atitude ecologicamente consciente e comportamento de reciclagem é mais forte. Alguns estudos de Guagnano, Stern e Dietz (1995) encontraram suporte empírico para essa hipótese em um estudo de reciclagem. A figura 2 ilustra o modelo ABC aplicado ao caso da reciclagem (Jackson, 2005, p.92). 
Figura 2: Modelo $A B C$ de Stern aplicado à reciclagem.

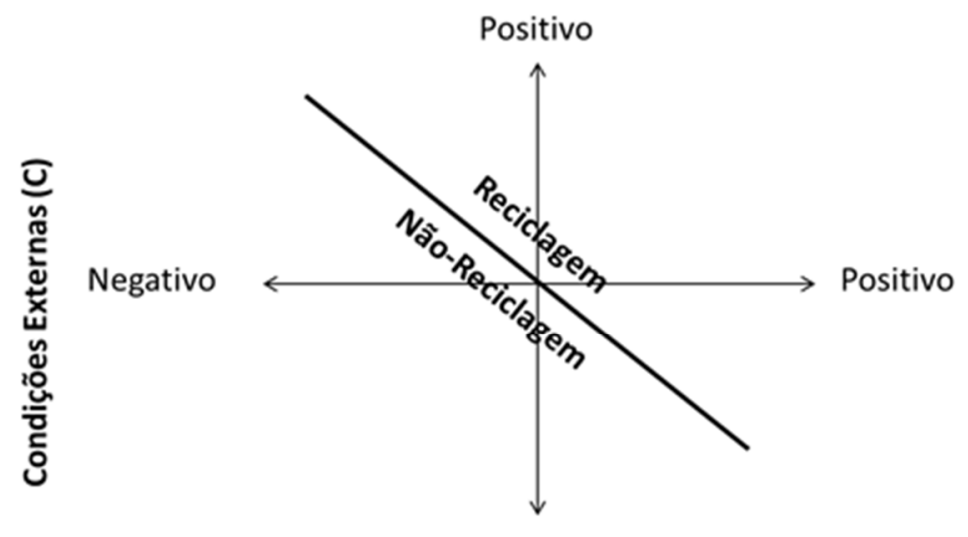

Negativo

Atitudes (A)

Fonte: Adaptado de Jackson (2005, p. 92).

\section{O Hiato e as Gerações}

As gerações são constituídas por pessoas que nasceram durante um determinado período e cujos cursos de vida correspondem entre si. Segundo a teoria geracional, os membros de cada geração são distintos dos de outra geração em termos de suas características, valores e crenças, interesses e expectativas (Strauss e Howe, 1997). De acordo com Rahulana et al. (2013), aqueles que nasceram no mesmo período de tempo compartilham comportamentos e valores similares e, portanto, podem ser segmentados e direcionados de acordo com os comportamentos de compra semelhantes que os retratam como um grupo.

Algumas abordagens de segmentação bastante conhecidas empregam variáveis descritivas tais como métodos demográficos e geográficos, juntamente com abordagens psicográficas que tentam ir além da superfície dos consumidores, a fim de compreender a motivação de compra, entre outras questões comportamentais. No entanto, a questão comportamental de "por que os consumidores compram ou consomem" é de grande importância na elaboração e implementação de estratégias para as organizações.

A partir da tipologia encontrada na literatura específica classificando as gerações em: geração silenciosa, geração baby boomer, geração $X$ e geração $Y$, este estudo adotou os critérios de Kotler e Keller (2012), que consideram indivíduos da geração baby boomer como aqueles nascidos entre 1946 e 1964 e indivíduos da geração Y como aqueles nascidos entre 1979 e 1994.

No que diz respeito à relação das gerações com o meio ambiente, Li, Li e Hudson (2013) observam que o atributo qualidade ambiental difere de forma mais marcante entre as gerações baby boomer e $\mathrm{Y}$. Os autores consideram que os baby boomers atribuem mais importância à qualidade ambiental do que a geração Y. No entanto, isso contradiz pesquisa realizada pelo The Intelligence Group (2012) que constatou que a proteção do meio ambiente é uma preocupação fundamental para a geração $\mathrm{Y}$. 


\section{Síntese Conceitual}

A figura 3 apresenta uma síntese dos principais fatores externos e internos encontrados na revisão de literatura e apontados como agentes influentes e causadores do hiato que são explorados nesta pesquisa. Optu-se por dividi-los em fatores internos e externos ao indivíduo.

\section{Figura 3- Síntese dos fatores que podem causar o hiato atitude-comportamento}
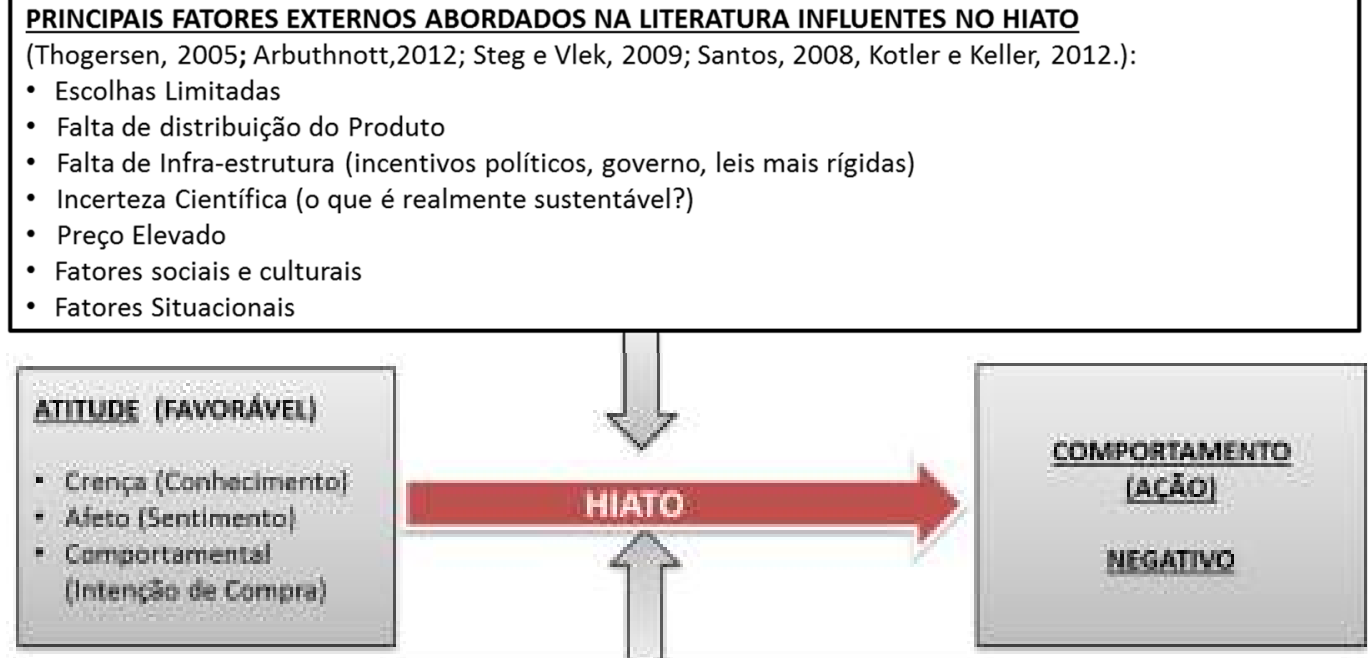

PAINCIPAIS FATORES INTERNOS ABORDADOS NA UTERATURA INFLUENTES NO HIATO

(Thogersen, 2005; Arbuthnott,2012; Steg e Vlek, 2009; Santos, 2008, Kotler e Keller, 2012):

- Tempo e Recursos Financeiros

- Capacidade de Interpretação das Informações

- Conhecimento Limitado do Indivíduo

- Dificuldade de mudar hábitos

- Dificuldade de mudar necessidades psicológicas e sociais (expressão de identidade e status)

- Motivação, necessidade e desejo

- Percepção

- Valores pessoais

- Estilos de Vida

Fonte: elaborada pelos autores

\section{METODOLOGIA}

A abordagem utilizada neste estudo é adequada a sua natureza exploratória. Assim, se escolheu a entrevista em profundidade como método de pesquisa qualitativa, pois esta permite aprofundar a compreensão sobre o fenômeno investigado (Creswell, 2010).

Após a pesquisa bibliográfica que identificou alguns modelos que tentam explicar o hiato e os principais fatores que o afetam, foi realizada a pesquisa de campo, entrevistando-se indivíduos de dois grupos geracionais: geração baby boomer, os nascidos entre 1946 e 1964; e geração Y, ou seja, aqueles nascidos entre 1979 e 1994. Esta abordagem é ao mesmo tempo transversal e retrospectiva, pois se enfocam comportamentos atuais, mas se busca entender como tais comportamentos se forjaram ao longo do tempo.

Todos os entrevistados residem na cidade do Rio de Janeiro e informaram ter atitudes e comportamentos ecologicamente conscientes. Foram analisados cinco tipos de consumo sustentável na pesquisa maior, porém este artigo se restringe a apenas uma categoria: descarte e reciclagem de lixo, o que 
engloba a preocupação com o descarte de lixo na natureza, uso de coleta seletiva, separação do lixo, forma de descarte de lixo eletrônico (pilhas, celulares, baterias, cartuchos etc.); forma de lidar com sacolas plásticas recebidas no supermercado etc.

Os sujeitos da pesquisa foram selecionados por meio da técnica bola de neve (Creswell, 2010), tendo sido entrevistados quinze consumidores pertencentes à geração baby boomer, sendo sete homens e oito mulheres. Paralelamente também foram entrevistados oito homens e sete mulheres da geração $Y$. Todos os indivíduos pertencem às classes $A$ e $B$ com renda familiar superior a $R \$ 3.500,00$, garantindo maior homogeneidade entre os dois grupos amostrais (ABEP, 2008).

As entrevistas foram realizadas seguindo inicialmente um roteiro estruturado de perguntas abertas e os entrevistados foram estimulados a exprimir sentimentos, intenções e crenças, a relatar características pessoais e experiências passadas. A seguir foi aplicado um questionário, baseado no questionário de comportamento do consumidor consciente do Instituto Akatu (2013), com questões fechadas sobre determinadas atividades cotidianas e de consumo que refletiriam um comportamento ecologicamente consciente ou não, medidas por uma escala de frequência (nunca, raramente, às vezes, com frequência e sempre). Caso o hiato entre atitude e comportamento fosse detectado, buscava-se entender mais profundamente, as motivações do entrevistado. Para preservar o anonimato dos entrevistados, eles serão mencionados na análise apenas pelo seu número (de 1 a 30 ) seguido da letra $\mathrm{M}$ ou $\mathrm{F}$ para indicar seu sexo.

Os dados foram tratados por meio de análise de conteúdo, com uso do software Atlas.ti, versão 7.0. Com base em Rubin e Rubin (2004) e Creswell (2010), foram comparados os códigos formados a partir das informações obtidas, verificando semelhanças e diferenças entre as entrevistas. Foram analisados grupos de categorias de fatores identificados na literatura (entorno físico, estímulos externos, lócus de controle, valores e influências, motivações, percepção de produtos, aprendizado, conhecimento) a fim de destacar os principais fatores influentes no hiato entre atitude e comportamento ecologicamente consciente dos consumidores em cada geração. A técnica de análise é a comparação dos padrões encontrados (pattern-matching), tanto entre as atividades de consumo quanto entre as gerações. Por fim, procedeu-se à interpretação dos resultados obtidos.

Esta pesquisa apresenta como principal limitação metodológica, inerente a pesquisas qualitativas com pequena amostra, a impossibilidade de realizar generalizações estatísticas, sendo, porém, possível realizar generalizações analíticas.

\section{APRESENTAÇÃo E ANÁLISE dOS RESULTADOS}

O tema do descarte/reciclagem mobilizou fortemente os entrevistados das duas gerações e aparece associado a diversos fatores. A seguir, apresentam-se separadamente análises referentes a lixo, lixo eletrônico e a descarte de sacolas plásticas. Embora a análise tenha sido realizada separadamente para cada geração, a apresentação dos resultados é feita para cada fator confrontando-se as perspectivas das duas gerações analisadas, intercalando-se extratos de entrevistas que ajudam a exemplificar e caracterizar os fatores identificados. 


\section{Descarte e, ou Reciclagem de Lixo}

O lixo recebeu grande atenção por parte de entrevistados da geração baby boomer (BB) e da geração $\mathrm{Y}$, estando associado a diversos fatores vistos como responsáveis pelo hiato entre atitude e comportamento ecologicamente consciente. O Quadro 1 resume os fatores indicados por cada geração em associação com o lixo, tendo-se agrupado os mesmos em grandes categorias e em categorias menores (ou subcategorias).

Embora os entrevistados de ambas as gerações estejam preocupados com o descarte de lixo, essas preocupações apresentam nuances específicas por geração. Os entrevistados da geração BB mencionam tanto o ato de não jogar lixo na rua, quanto a separação e a coleta seletiva. Já os entrevistados da geração Y enfatizam mais a questão da separação do lixo e da coleta seletiva. Entre os entrevistados da geração BB seis mencionaram a questão da coleta seletiva $(16 \mathrm{M}, 20 \mathrm{~F}, 23 \mathrm{~F}, 24 \mathrm{M}, 25 \mathrm{~F}, 27 \mathrm{~F})$ versus 12 entrevistados da geração $\mathrm{Y}(1 \mathrm{M}, 2 \mathrm{~F}, 4 \mathrm{M}, 5 \mathrm{M}, 7 \mathrm{~F}, 9 \mathrm{M}, 10 \mathrm{~F}, 11 \mathrm{M}, 12 \mathrm{~F}, 13 \mathrm{~F}, 14 \mathrm{M}, 15 \mathrm{M})$. Em comparação, cinco entrevistados da geração $B B(16 \mathrm{M}, 21 \mathrm{~F}, 23 \mathrm{~F}, 25 \mathrm{~F}, 26 \mathrm{~F})$ versus dois da geração $\mathrm{Y}(6 \mathrm{~F}, 9 \mathrm{M})$ mencionaram a questão de jogar lixo na rua.

Quadro 1 - Fatores que afetam o Hiato nas Gerações BB e Y

\begin{tabular}{|l|l|l|}
\hline \multicolumn{1}{|c|}{ Categoria } & \multicolumn{1}{|c|}{ Fatores - geração BB } & \multicolumn{1}{c|}{ Fatores - geração Y } \\
\hline Entorno físico & Infraestrutura & Infraestrutura \\
\hline Estímulos Externos & $\begin{array}{l}\text { Falta de estímulo regulatório } \\
\text { Falta de divulgação }\end{array}$ & Lócus de controle interno \\
\hline Lócus de controle & Lócus de controle interno e externo & Influências sociais \\
\hline Valores & Diferenças culturais & $\begin{array}{l}\text { Motivação econômica } \\
\text { Motivação ambiental } \\
\text { Preocupação moral e normativa } \\
\text { Motivações }\end{array}$ \\
\hline Preocupação moral e normativa & Preocupação social \\
\hline Aprendizado & Preguiça & Preguiça \\
\hline Conhecimento & Conhecimento limitado & Conhecimento limitado \\
\hline
\end{tabular}

Fonte: elaborada pelos autores. 
Tanto entrevistados da geração BB (17F, 21F, 23F, 24M, 25F, 27F) quanto da geração $\mathrm{Y}(1 \mathrm{M}, 2 \mathrm{~F}$, $4 \mathrm{M}, 5 \mathrm{M}, 7 \mathrm{~F}, 9 \mathrm{M}, 11 \mathrm{M}, 12 \mathrm{~F}, 14 \mathrm{M}$ ) citaram o problema de ausência de infraestrutura local para coleta seletiva adequada, considerando que não adianta o cidadão fazer a parte dele se não há um sistema de coleta seletiva pública implantado pelo governo de forma eficaz. Os extratos de depoimentos dos entrevistados da geração $\mathrm{BB}$, a seguir, são bastante enfáticos em relação à dificuldade infraesrutural na coleta de lixo:

- (21F): "Falta lixeira nas ruas, nas praias, e quando têm, elas são muito pequenas!"

- (27F): "Porque, eu tenho lá embaixo um espaço em que guardo as latas de lixo separadas, então eu vou acumulando para poder reciclar. O que é muito difícil, porque a Comlurb passa uma vez por semana, às vezes não passa, depois os catadores pegam, abrem o lixo, fica tudo espalhado pela calçada. Então, temos essa dificuldade na coleta urbana".

Já a entrevistada $25 \mathrm{~F}$, proprietária de uma loja de produtos homeopáticos em Ipanema, explica o trabalho de coleta seletiva da Comlurb (coleta de lixo na cidade do Rio de Janeiro), que antes passava uma vez ou duas vezes por semana e deixou de passar. Além disso, houve a mudança da lei em 2014, mudando o horário de coleta do caminhão de lixo. Ela explica que durante 30 anos, a coleta sempre foi realizada às 19 horas, mas, com a nova lei, passou a ser realizada às 20 horas. Agora, seus funcionários estão sofrendo com a situação, uma vez que só podem colocar o lixo para fora da loja às 20 horas, caso contrário a empresa é multada, mas a empresa fecha às 19 horas.

Os resultados das entrevistas com membros da geração $Y$ também apontam deficiências de infraestrutura como fator importante para o aumento do hiato entre atitude e comportamento ecologicamente consciente. Eles também percebem a falta de um sistema público de reciclagem e coleta de resíduos, o que dificulta o comportamento ecologicamente consciente do consumidor com relação aos temas de descarte e reciclagem, como se verifica nos depoimentos a seguir:

- $\quad$ (7F): "O nosso prédio não tem coleta seletiva. Então, se a gente separar, o porteiro vai lá e junta tudo, porque é o sistema normal da Comlurb que passa, não tem nenhuma coleta seletiva. A não ser que a gente pegue e leve para outro lugar que tenha coleta".

- $\mathrm{R}(2 \mathrm{~F})$ : "A questão de reciclagem... Por exemplo, hoje eu estou casada e moro em prédio. Meu prédio faz coleta seletiva. Então, ok, separo o lixo. Mas eu tenho uma amiga que queria reciclar, mas o prédio dela não fazia. Aí ela desistiu".

Esses resultados corroboram os estudos de Steg e Vlek (2009) e Santos (2008), que afirmam que fatores contextuais externos podem facilitar ou restringir o comportamento ambiental e influenciar as motivações individuais, citando como exemplo que a disponibilidade de instalações de reciclagem, a qualidade do transporte público e o fornecimento de bens de mercado podem afetar fortemente 0 envolvimento das pessoas em um comportamento ecologicamente consciente.

Com relação à falta de estímulos externos, salientam-se apenas comentários de membros da geração BB (16M, 21F, 23F, 25F), não tendo sido registrados comentários da geração Y. Esses depoimentos estão relacionados à questão de jogar lixo na rua e não à coleta seletiva. 
Entrevistados da geração BB reclamam da falta de divulgação eficaz sobre as causas dos problemas ambientais. A entrevistada $21 \mathrm{~F}$ menciona a falta de divulgação e cita o exemplo da guimba de cigarro. Ela só descobriu que havia local apropriado para apagar o cigarro na lixeira pública depois de obter essa informação na televisão:

- (21F): "Eu não sou fumante. Então eu não sabia que naquela lixeira tinha espaço para apagar o cigarro. Na lixeira pública tem um espaçozinho assim, tem um metal que você apaga o seu cigarro e joga fora. Como eu não fumo, eu não sabia. Mas fiquei sabendo por quê? Eu fui assistir ao programa em que eles estavam trabalhando a questão do lixo, aí multaram uma pessoa que jogou um cigarro no chão".

Já a entrevistada $25 \mathrm{~F}$ comenta quanto à importância de conscientizar a população das consequências do lixo que é jogado na rua. Ela diz que esse lixo traz sérios danos à população, e que faz parte do papel do governo, a questão de educar, informar, conscientizar, e criar campanhas informativas para onde vai o lixo. Ela acredita que essas campanhas deveriam mostrar o destino desse lixo, apresentando fotos de poluição ambiental das águas, dos mares, das enchentes durante as épocas de chuvas fortes, causadas por problemas de entupimento de bueiros. Segundo a entrevistada, essas campanhas são essenciais porque muitas vezes o povo não tem essa consciência.

Nota-se pelas respostas, que um estímulo externo percebido como relevante para a redução do hiato seriam as campanhas de educação do consumidor e outras formas de divulgação de práticas ambientais, ou voltadas para facilitar as ações ecologicamente conscientes. Este ponto também é abordado no estudo de Arbuthnott (2012), no qual a autora chama a atenção para a importância de realização de campanhas públicas para divulgação dos problemas ambientais.

Consonante com os estudos de Thogersen (2005), muitos entrevistados citaram a falta de regulamentação e de fiscalização (estímulo regulatório) por parte do governo, enfatizando a necessidade de leis e regras serem cumpridas a fim de diminuir o hiato. Eles afirmam que faltam leis mais rígidas para educar o cidadão sobre a questão de jogar lixo na rua, citam o descaso do governo com o entorno social, culpam o governo por não ter um sistema de coleta seletiva de lixo disponível ao cidadão e mencionam a necessidade de haver leis de logística reversa.

Por exemplo, os entrevistados 21F e 23F da geração BB citam a importância da punição econômica para os cidadãos (como por exemplo, campanha Lixo Zero), como forma de educá-los para questões ambientais.

- (21F): "Questão de educação é o bolso e são as leis rígidas do país que formam o comportamento do cidadão. O consumidor só aprende, só é educado quando começa a doer no bolso".

- (23F): "Eu acho assim, se mexer no bolso, jogar lixo, guimba no chão, a pessoa sabe que vai ser multada, a pessoa começa a se educar". 
O fator lócus de controle aparece relacionado ao lixo nos depoimentos de quatro entrevistados (26F, $1 \mathrm{M}, 4 \mathrm{M}$ e 13F). O discurso dos entrevistados da geração $Y$ parece ser indicativo de lócus de controle interno, ou seja, os membros desta geração entrevistados parecem acreditar que as mudanças necessárias no mundo dependem em grande parte do próprio indivíduo e que suas ações podem contribuir significativamente para criar um mundo melhor, principalmente no que tange o tema do descarte / reciclagem. Por exemplo:

- (1M) da geração Y: "Agora, a consciência de você estar andando, ver lixo no chão e recolher o lixo, é assim... acho que a população é responsável por tudo. Então às vezes a gente fala 'Ah, sujaram a rua', mas se você pode recolher e jogar no lixo, isso já é um ato de consciência. [...]. E acho que, não sei se pelo amadurecimento, mas eu passei a enxergar a minha responsabilidade nisso também. E eu vou fazer o melhor que eu puder pelo planeta".

Já entre os membros da geração BB, os dois tipos de lócus (interno e externo) estão presentes, sugerindo que para indivíduos de gerações mais antigas, pode haver uma certa descrença para com a efetividade de suas iniciativas. Não obstante, como já observado, a natureza do presente estudo não permite fazer generalizações a este respeito para a população.

Em relação à categoria dos valores e Influências, por serem aprendidos muito cedo na vida, os valores se encontram muito enraizados e, por vezes, as pessoas sequer têm consciência deles. Por isso mesmo, é difícil identificar valores a partir de depoimentos. Nas entrevistas realizadas, os entrevistados recorrem a comparações entre culturas, subculturas e classes sociais para falar de valores relativos à consciência ecológica.

Entre os entrevistados da geração $\mathrm{Y}$, ficou evidenciado que as influências sociais mais relevantes mencionadas na questão do descarte e reciclagem provêm da família,

- (6F): "A preocupação ambiental, eu acho que também foi uma coisa ensinada na família mesmo. Um conceito que veio de família. Amigos, nem todos têm essa preocupação, depende, alguns grupos de amigos têm uma preocupação, outros não. Às vezes, você tem até que dar uma dica, falando 'ô, não deixa isso aí', quando alguém quer jogar algum lixo fora no chão. Quando é meu amigo, eu falo. Mas quando é uma pessoa da rua, eu não falo não. Mas eu queria falar, as pessoas em geral são muito mal educadas."

- (3M): "A minha mãe é bióloga, ela tem essa consciência ambiental. Então, desde cedo eu estou acostumado a ouvir dela: 'ah, apaga a luz!' Tentar pensar no meio ambiente, sempre houve essa preocupação por parte dela. Agora, meu pai, eu acho que ele não tem muita preocupação. [...] Esse negócio de fio dental aqui em casa, não jogamos no vaso, jogamos no lixo, porque minha mãe já falou que causa grandes problemas, porque o fio acaba enrolando, nos reservatórios, nas coisas de esgoto". 
Já na geração $B B$, atribui-se também a prática de jogar o lixo na rua a questões culturais, em contraposição a certas culturas estrangeiras (16M, 25F).

- (16M) da geração BB: "Nos Estados Unidos não tem lixo orgânico porque ele é todo triturado e vai na água. Então você não tem lixo orgânico. Aqui o maior problema ambiental é o lixo orgânico. É o resto de comida. E a classe média é mestre nisso, fazendo grande quantidade de comida. A classe média é um problema do desperdício porque rico não desperdiça não. E a classe média desperdiça muito. O nosso lixo orgânico é impressionante!"

Outros entrevistados da geração BB $(20 \mathrm{~F}, 25 \mathrm{~F}, 9 \mathrm{M}, 2 \mathrm{~F}, 10 \mathrm{~F}, 11 \mathrm{M})$ se referem à cultura da pobreza, ao comentar que as comunidades carentes jogam muito lixo na rua, não possuem consciência ambiental, e que o lixo gera consequências sérias para a população, como entupimento dos bueiros e poluição da água. Esta visão tem um viés das classes sociais a que pertencem os entrevistados ( $A$ e B). Ainda que não estejam totalmente erradas, ignoram que tal comportamento também acontece entre cidadãos mais abastados.

A motivação ambiental predomina entre as motivações mencionadas, com diversos entrevistados da geração $Y$ indicando que o comportamento de separação de lixo está associado a uma preocupação com o ambiente. Possuir uma alta motivação ambiental pode contribuir de forma muito positiva para diminuir o hiato, uma vez que o indivíduo estará mais atento e consciente para questões de problemática ambiental e tentará realizar ações mais coerentes com suas atitudes. O entrevistado 28M desta geração diz que, devido a sua consciência e motivação ambiental, ele sempre tenta separar o lixo orgânico de garrafa pet e só imprime papeis se for estritamente necessário. Além disso, foi o único respondente a informar que toma banho rápido por uma questão de hábito e, ao mesmo tempo, para tentar reduzir o consumo de água:

Já no que se refere às preocupações morais e normativas, essas aparecem nas duas gerações, mas enquanto os entrevistados da geração BB não aceitam que se jogue lixo na rua, os da geração $Y$ falam de como o exemplo de alguns na coleta seletiva pode inspirar outros. Por fim, aparece também apenas entre entrevistados da geração $Y$ a preocupação social associada à coleta de lixo, com menções aos catadores (5M e 9M) e ao Exército da Salvação (7F).

Finalmente, a relação de fatores associados ao lixo inclui ainda a preguiça, já que a coleta seletiva é trabalhosa (16M, 2F, 9M), e o conhecimento limitado sobre o destino que se dá ao lixo e como proceder para realizar coleta seletiva ou descarte de produtos específicos $(24 \mathrm{M}, 16 \mathrm{M}, 5 \mathrm{M}, 11 \mathrm{M}, 12 \mathrm{~F}, 15 \mathrm{M})$. Estas informações corroboram parcialmente o modelo de Blake (1999).

\section{Descarte e, ou Reciclagem de Lixo eletrônico}

Com relação especificamente ao descarte de lixo eletrônico (pilhas, celulares, baterias, computadores, cartuchos etc.) alguns entrevistados da geração BB e outros da geração $Y$ se manifestaram. Alguns entrevistados de ambas as gerações (6F, 9M, 3M, 20F, 27F) apontam motivação tanto ambiental quanto econômica para utilizar a recarga do cartucho de tinta. Vários entrevistados de ambas as gerações dizem possuir um local específico para armazenar lixo eletrônico, mas chamam a atenção para a dificuldade para descartá-lo (7F, 9M, 26F, 23F). Eles não jogam os cartuchos usados no lixo comum porque têm 
consciência de que isso poluirá o meio ambiente, mas não têm informações sobre onde deve ser realizado este descarte, daí disporem de um local de depósito para guardar esse lixo até encontrarem um destino final para ele.

Uso de sacolas plásticas descartáveis ao invés de reutilizáveis

Também com relação ao uso de sacolas plásticas foi baixo o número de fatores identificados associados ao hiato entre atitude e comportamento ecologicamente responsável. Os fatores identificados com relação ao descarte de sacolas plásticas são apresentados no Quadro 2.

Quadro 2: Diferenças entre Fatores Responsáveis pelo Hiato em relação ao uso de sacolas plásticas no Discurso das Gerações BB e Y

\begin{tabular}{|l|l|l|}
\hline \multicolumn{1}{|c|}{ Categoria } & \multicolumn{1}{|c|}{ Fatores - geração BB } & \multicolumn{1}{c|}{ Fatores - geração $\mathbf{Y}$} \\
\hline Valores & Diferenças culturais & Influências sociais \\
\hline Motivações & & Motivação ambiental \\
\hline Aprendizado & Conveniência de uso & Conveniência de uso \\
\hline
\end{tabular}

Fonte: elaborada pelos autores

Pode-se observar certo consenso entre as gerações com relação à conveniência de uso das sacolas plásticas descartáveis adquiridas nos supermercados. Diversos entrevistados da geração $\mathrm{Y}(1 \mathrm{M}, 4 \mathrm{M}, 6 \mathrm{~F}, 10 \mathrm{~F}$, $11 \mathrm{M})$ e da geração BB (20F, 21F, 23F, 26F, 29F) dizem reaproveitar essa sacola plástica para outras finalidades, como utilizá-la no lixinho de banheiro, como saquinho para coletar dejetos de seu animal de estimação, ou como saco de lixo na pia da cozinha.

Entrevistados da geração BB mencionaram que as idas ao supermercado nem sempre são planejadas, ou seja, a situação e o contexto da compra determinam se levarão a sacola retornável ou não. Vários entrevistados da geração $\mathrm{Y}(2 \mathrm{~F}, 3 \mathrm{M}, 13 \mathrm{~F}, 15 \mathrm{M})$ realizaram comparações do uso de sacolas plásticas nos supermercados no Brasil com supermercados no exterior (França, Inglaterra). Alguns entrevistados afirmam que deveria haver leis para banir o uso de sacolas plásticas nos supermercados e falta de estímulo econômico para dar aos consumidores alguma forma de incentivo para usar ecobags (15M, 3M, 4M).

- (2F): "Dá até desânimo. Eu viajo muito pra fora. E converso muito com as pessoas no exterior. $E$ elas ficam chocadas com muitas coisas do brasileiro. Aqui vários prédios não fazem reciclagem. Lá a maioria dos prédios faz reciclagem. [...] O pessoal lá de fora fica horrorizado com esse desperdício que a gente tem. Porque lá tem lugares que, até se você quiser sacola no supermercado, você tem que pagar pela sacola. Então você diz 'quero uma sacola, duas sacolas', e paga pela sacola. Aqui não. Aqui tem sacola esbanjando. A gente vê a realidade lá fora e vê que aqui, realmente, é um desperdício geral."

- (15M): "A última vez que eu fui para a França, enfim, falo mais ou menos francês, não muito bem. Mas aí a mulher do caixa, falou uma coisa, eu não entendi. Ela estava me alertando que eles não trabalham com sacola plástica. Então na hora que eu fui lá, eu não tinha sacola e estava com tudo nas mãos para passar no caixa, então, enfim, eles te obrigam a ter a sua ecobag. Tive que 
voltar e comprar uma ecobag, porque eu tentei botar na mochila, mas era muita coisa, estava num albergue, então não coube na mochila que eu tinha."

Entrevistados da geração $Y$ opinaram que no Brasil há um desperdício de sacolas, pois elas são facilmente acessíveis aos clientes, o que contribui de certa forma para aumentar o hiato. Por mais que a pessoa tenha uma atitude favorável, as leis, o contexto, e a situação no próprio supermercado não banem o uso da sacola plástica descartável, gerando assim um maior descarte deste produto.

\section{CONCLUSÕES}

A partir dos resultados apresentados, a primeira questão de pesquisa deste estudo ("Quais os principais fatores influenciadores no hiato entre atitudes e comportamento ecologicamente conscientes nas gerações BB e Y?") foi respondida identificando-se diversos fatores que aumentam ou reduzem o hiato no que diz respeito ao descarte de lixo e à reciclagem, comparando-se os dois grupos geracionais.

Assim, foi desenvolvido um esquema conceitual que reúne os fatores identificados no decorrer do estudo, classificando-os em três grandes grupos: fatores antecedentes, fatores que reduzem o hiato e fatores que aumentam o hiato. A figura 4 apresenta o esquema conceitual proposto, podendo-se observar que nem todos os fatores deste modelo influenciam o hiato especificamente para o descarte de lixo e reciclagem de materiais, de acordo com as respostas dos entrevistados, mas a maioria deles está presente, como está explicitado na figura 2. Este modela contempla algumas das variáveis propostas nos modelos estudados anteriormente de Blake (1999) e Stern (2000). Uma proposição a ser testada é que os fatores que explicam o hiato entre atitude e comportamento ecologicamente conscientes podem diferir em função da atividade de consumo e até do tipo de produto, como ocorreu no caso de sacolas plásticas.

Com relação à segunda questão de pesquisa ("Os fatores influenciadores do hiato identificados afetam de forma distinta os membros das gerações $B B$ e $Y$ ?"), os resultados obtidos no estudo indicam que a resposta a esta pergunta é afirmativa para a amostra de entrevistados analisados, levando à proposição a ser testada de que indivíduos de diferentes gerações podem ser afetados de forma distinta pelos fatores que aumentam/reduzem o hiato entre atitudes e comportamento ecologicamente conscientes.

No caso do descarte de lixo e reciclagem de materiais, podem ser destacadas diferenças de comportamento entre os membros da geração baby boomer e da geração $\mathrm{Y}$, corroborando o estudo de Li, Li e Hudson (2013) que afirmam que é de se esperar que cada geração exiba padrões de comportamento de consumo semelhantes entre si e diferentes das gerações anteriores e posteriores. No entanto, as conclusões desta pesquisa sugerem que os membros da geração $Y$ na amostra estudada apresentam motivação ambiental e social tão grande quanto, e em alguns casos, maior que, os da geração baby boomer, contradizendo os achados de Li, Li e Hudson (2013) e aproximando-se mais dos resultados da pesquisa do The Inteligence Group (2012). Além disso, a exposição precoce dos membros dessa geração às influências positivas vindas da geração de seus pais (baby boomers) e de outras culturas (seja por meio de viagens ou contatos via internet) torna os membros da geração $Y$ melhor informados e potencialmente mais sensíveis e proativos à questão do lixo e da reciclagem. 
Figura 4: Esquema conceitual proposto para descarte de lixo e reciclagem

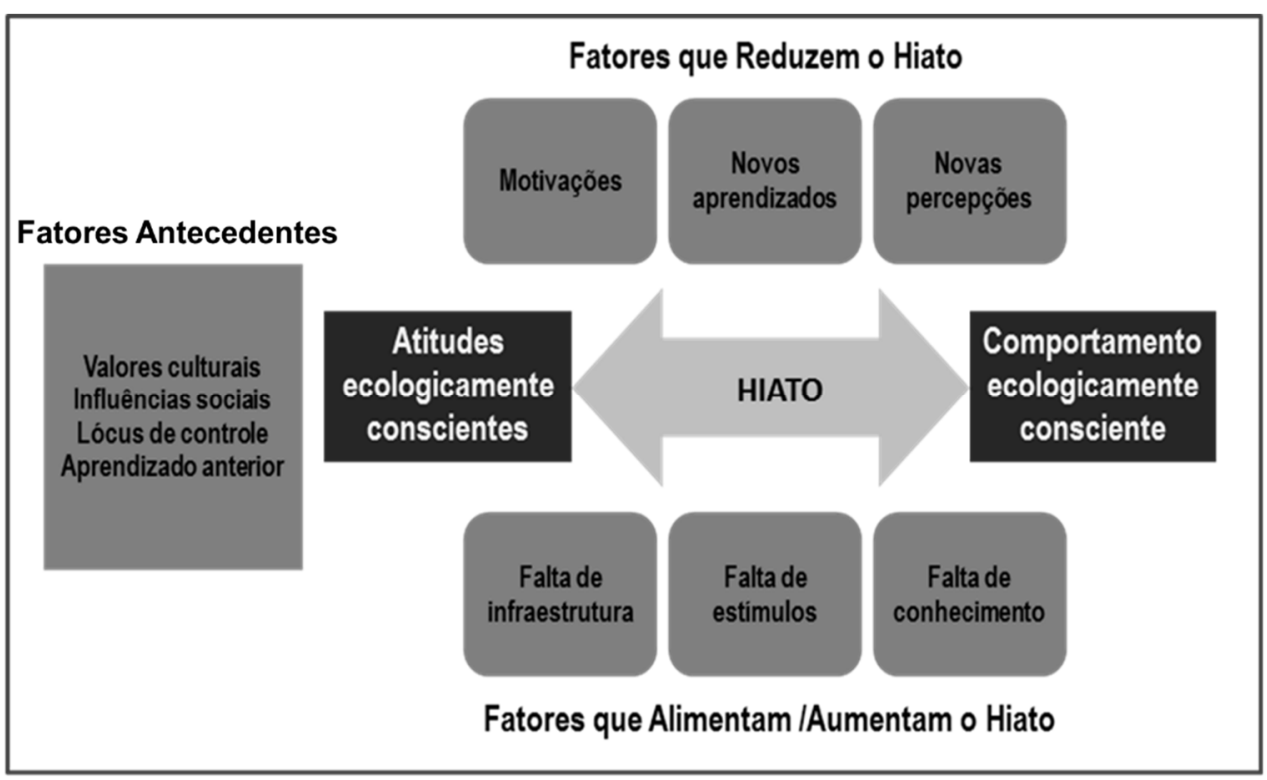

Fonte: elaborada pelos autores

Como limitação evidenciada, o presente estudo analisa unicamente o hiato entre atitudes e comportamento de indivíduos residentes na cidade do Rio de Janeiro, pertencentes à classe A e B. Talvez, indivíduos de culturas de outros países ou até mesmo de outras regiões dentro do Brasil apresentem resultados um pouco diferentes, visto que o contexto situacional, os valores culturais, sociais, pessoais, as percepções, os fatores externos de estímulos e infraestrutura variam entre países e regiões. A ampliação da amostra e dos produtos e serviços analisados é uma sugestão para futuros trabalhos.

\section{REFERÊNCIAS}

ABEP, Associação Brasileira de Empresas de Pesquisa. Critério de Classificação Econômica Brasil: Dados, 2008. Disponível em: <http://www.abep.org/novo/Content.aspx?SectionID=84> . Acesso em: 18 nov. 2013.

ARBUTHNOTT, K. D. Sustainable Consumption: Attitudes, Actions, and Well-Being. Analyses of Social Issues and Public Policy, v. 12, n. 1, p.204-208, 2012.

BLAKE, J. Overcoming the 'value-action gap' in environmental policy: tensions between national policy and local experience. Local Environment, v. 4, n. 3, p. 257-278, 1999.

BUGERA, J.; LENGYEL, C.; UTIOH, A.; ARNTFIELD, S. Baby boomers' acceptability of a tomato lentil pasta sauce. Food Research International. v. 52, n. 2 p. 542-546, 2013.

CRESWELL, J. Projeto de Pesquisa. Métodos qualitativos, quantitativos e misto. 3a. ed. Porto Alegre: Artmed, 2010. FRIEND, G. The truth about Green Business. NJ: Natural Logic Inc, 2009.

GATERSLEBEN, B. Affective and symbolic aspects of car use. In T. Garling, \& L. Steg (Eds.), Threats to the quality of urban life from car traffic: Problems, causes, and solutions (p. 219-233). Amsterdam: Elsevier, 2007.

GUAGNANO, G; STERN, P.; DIETZ, T. Influences on Attitude Behavior Relationships - a natural experiment with curbside recycling. Environment and Behavior, v. 27, n. 5, p. 699-718, 1995.

HINES, J.M., HUNGERFORD, H.R. \& TOMERA, A.N. Analysis and synthesis of research on responsible proenvironmental behavior: a meta-analysis. The Journal of Environmental Education, v. 18, n. 2, p. 1-8, $1986-87$.

INSTITUTO AKATU. Pesquisa $n^{\circ} .7$ - 2006: Como e por que os brasileiros praticam o consumo consciente? $1^{\mathrm{a}}$. ed. São Paulo: Instituto Akatu, 2007. Disponível em: <http://www.akatu.org.br/Content/Akatu/Arquivos/file/Publicacoes/19Pesquisa7.pdf>. Acesso em: 11 nov. 2013. 
JACKSON, T. Motivating Sustainable Consumption - a review of evidence on consumer and behavioral change. University of Surrey, Sustainable Development Research Network, UK. 2005, 170 p.

KOLLMUSS, A.; AGYEMAN, J. Mind the Gap: why do people act environmentally and what are the barriers to proenvironmental behavior? Environmental Education Research, v. 8, n. 3, p. 239-260, 2002.

KOTLER, P.; KELLER, K. Administração de Marketing. 14 ed. São Paulo: Pearson Education do Brasil, 2012.

KUMAR, A., LIM, H. Age differences in mobile service perceptions: comparison of Generation $Y$ and baby boomer. Journal of Services Marketing, n. 227, p. 568-577, 2008.

LI, X.; LI, X. R.; HUDSON, S. The application of generational theory to tourism consumer behavior: An American perspective. Tourism Management, v. 37, p. 147-164, 2013.

MOSTAFA, M. A hierarchical analysis of the green consciousness of the Egyptian consumer. Psychology and Marketing, v. 24, p. $445-473,2007$.

OTTMAN, J. A. Green Marketing: Opportunity for innovation. 2 ed. New York: BookSurge, 1998.

OTTMAN, J. A.; STAFFORD, E.R.; HARTMAN, C.L. Avoiding green marketing myopia: ways to improve consumer appeal for environmentally preferable products. Environment: Science and Policy for Sustainable Development, v. 48, n.5, p. 22-36, 2006.

PAÇO, A. M. F.; RAPOSO, M., L. B. Green consumer market segmentation: empirical findings from Portugal. International Journal of Consumer Studies, v. 34, p. 429-436, 2010.

PADEL, S.; FOSTER, C. Exploring the gap between attitudes and behaviour: Understanding why consumers buy or do not buy organic food. British Food Journal, v. 107, n. 8, p. 606-625, 2005.

POMARICI, E.; VECCHIO, R. Millennial generation attitudes to sustainable wine: an exploratory study on Italian consumers. Journal of Cleaner Production, v. 66, p. 537-545, 2014.

PRIDE, W. M.; FERREL, O.C. Marketing Conceitos e Estratégias. Rio de Janeiro: LTC, 2001.

RAHULAN, M.; TROYNIKOV, O.; WATSON, C.; JANTA, M.; SENNER, V. Consumer Purchase Behaviour of Sports Compression Garments - A study of Generation Y and baby boomer Cohorts. Procedia Engineering. v. 60, p. 163-169, 2013.

ROBERTS, J. A. Green consumers in the 1990s: profile and implications for advertising', Journal of Business Research, v. 36, n. 3, p. 217-231, 1996.

ROBERTS, J. A.; BACON, D. R. Exploring the subtle relationship between environmental concern and ecologically conscious consumer behavior. Journal of Business Research, v. 40, p. 79-89, 1997.

RUBIN, H. J.; RUBIN, I. S. Qualitative Research: The Art of Hearing Data (Kindle Edition). Sage Publication, 2004.

RUNDLE-THIELE, S.; PALADINO, A.; APOSTOL, S.A.G., JR. Lessons learned from renewable electricity marketing attempts: A case study. Business Horizon, v. 51, p. 181-190, 2008.

SANTOS, G. The London experience. In E. Verhoef, B. Van Wee, L. Steg, \& M. Bliemer (Eds.), Pricing in road transport: A multi-disciplinary perspective (p. 273-292). Cheltenham: Edgar Elga, 2008.

STEG, L.; VLEK, C. Encouraging pro-environmental behaviour: An integrative review and research agenda. Journal of Environmental Psychology, v. 29, n. 3, p. 309-317, 2009.

STERN, P. C. Towards a coherent theory of environmentally significant behavior. Journal of Social Issues, n. 56, p. 407424, 2000..

STRAUSS, W.; HOWE, N. The fourth turning: An American prophecy. New York: Broadway Books, 1997.

THE INTELLIGENCE GROUP. (2012). The Cassandra good guide. Disponível em: <https://cmst130sec5.files.wordpress.com/2015/03/mediamemo.pdf>. Acesso em: 10 Jan. 2014.

THOGERSEN, J. Consumer behaviour and the environment: Which role for information? In Environment, information and consumer behaviour, eds., S. Krarup, and C. S. Russell, 51-63. Cheltenham, UK: Edward Elgar, 2005.

THOGERSEN, J.; SCHRADER, U. From Knowledge to Action-New Paths Towards Sustainable Consumption. Journal of Consumer Policy, v. 35, n. 1, p. 1-5, 2012.

URDAN, A. T.; URDAN, F. T. Marketing estratégico no Brasil: teoria e aplicações. São Paulo: Atlas, 2010. WELDFORD, R. Environmental strategy and sustainable development. Londres: Routledge, 1995.

YOUNG, W.; HWANG, K.; MCDONALD, S.; OATES, C. J. Sustainable Consumption: Green Consumer Behaviour when Purchasing Products. Sustainable Development, v. 8, p. 20-31, 2010. 